\title{
Effect of Ultrasound, Steaming, and Dipping on Bioactive Compound Contents and Antioxidant Capacity of Basil and Parsley
}

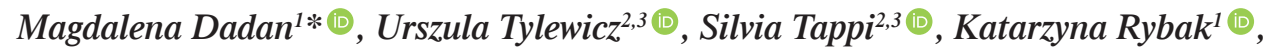 \\ Dorota Witrowa-Rajchert $^{1}{ }^{\circledR}$, Marco Dalla Rosa ${ }^{2,3}{ }^{(0)}$ \\ ${ }^{\prime}$ Department of Food Engineering and Process Management, Institute of Food Sciences, \\ Warsaw University of Life Sciences, Nowoursynowska 159c, 02-776 Warsaw, Poland; \\ katarzynarybak@sggw.edu.pl (K.R.),dorotawitrowarajchert@sggw.edu.pl (D.W.-R.) \\ ${ }^{2}$ Department of Agricultural and Food Sciences, Alma Mater Studiorium-Università di Bologna, \\ Piazza Goidanich 60, Cesena 47521, Italy; \\ urszula.tylewicz@unibo.it (U.T.),silvia.tappi2@unibo.it (S.T), marco.dallarosa@unibo.it (M.D.R.) \\ ${ }^{3}$ Interdepartmental Centre for Agri-Food Industrial Research, Alma Mater Studiorium-Università di Bologna, \\ Via Quinto Bucci, Cesena 47521, Cesena, Italy; \\ urszula.tylewicz@unibo.it (U.T.),silvia.tappi2@unibo.it (S.T),marco.dallarosa@unibo.it (M.D.R.)
}

Key words: basil, parsley leaves, ultrasound treatment, steaming, chlorophyll, lutein, total phenolic content

Fresh basil and parsley leaves are perishable and they are often processed by drying, which is an energy-consuming process and contributes to nutrient degradation. These downsides can, however, be mitigated by various pre-drying treatments. Thus, the objective of this study was to assess the impact of different treatments (ultrasound, steaming, dipping) and their duration (20,30 $\mathrm{min}$ ) on contents of chlorophylls and lutein (analyzed by UPLC-PDA), total phenolic content (TPC), as well as antioxidant capacity (determined as DPPH radical scavenging activity) in basil and parsley leaves. The changes in the chemical properties after treatments were more significant in the case of basil than parsley, probably due to a lower thickness of leaf epidermis layer and stiffness of the former. In comparison to fresh leaves, enhanced extractability of chlorophyll a after all treatments and TPC after dipping for $20 \mathrm{~min}$, was observed in basil. In parsley, instead, the chlorophyll content remained unchanged after treatments, but TPC decreased. Lutein content remained stable in both herbs following different treatments. Irrespectively of the treatment type, the TPC and antioxidant capacity were higher after 20 min of basil treatments, while in the case of parsley, higher TPC was determined after longer treatments (30 min). The study demonstrated that the investigated treatments could preserve or even enhance the chemical properties of herbs.

\section{INTRODUCTION}

Basil and parsley are seasoning herbs widely cultivated and distributed in a dried form to nearly every part of the world. They feature high antioxidant activity linked to the content of vitamin $\mathrm{C}$, carotenoids, phenolics, and other antioxidants [Boggia et al., 2015; Pérez-Gálvez et al., 2020; Śledź et al., 2013]. Currently, there is a lot of interest in their potential use as ingredients in functional foods, which is due to the high content of natural antioxidants (including phenolics) and essential oils [Ahmed et al., 2019; Liberal et al., 2020]. Certain compounds present in basil, especially quercetin and ursolic acid, have been proved to inhibit the formation of nitric oxide II - an inflammatory factor mediating cancer development. Its antiinflammatory properties have also been confirmed in the treatment of conjunctivitis and eyeball inflammation, skin diseases, and asthma; it has also been proved to act as an antipyretic agent [Kurian, 2012]. Also parsley can exhibit anti-inflammatory properties by reducing the secretion of histamine, as well as a multitude of other activities, like antipyretic, stimulating digestion, relieving bloating and colic, diuretic, carminative, stimulating menstruation, cleansing the liver and preventing kidney stones and gout [Charles, 2012; Kurian, 2012; Peter, 2012]. Many studies have shown the ability of its leaf extracts to scavenge free radicals [Charles, 2012; Liberal et al., 2020]. Moreover, studies have confirmed the antimutagenic effect of parsley apigenin and myristicin, which inhibited the activity of some enzymes responsible for pro-cancer transformations [Charles, 2012; Kurian, 2012]. Furthermore, such pigments as chlorophylls and carotenoids, apart from their role in photosynthesis and color perception, exhibit antimutagenic activity and antiseptic properties [Kopsell \& Kopsell, 2006; Wang

\footnotetext{
* Corresponding Author:

Tel.: +48 2259375 60; Fax: +48 2259375 76;

E-mail: magdalena_dadan@sggw.edu.pl (M. Dadan)
}

Submitted: 12 March 2021

Accepted: 16 August 2021

Published on-line: 2 September 2021 
et al., 2019]. It is worth emphasizing that many studies have proved the antioxidant activity of not only carotenoids but also chlorophylls, although they are not generally classified as antioxidants [Kopsell \& Kopsell, 2006; Pérez-Gálvez et al., 2020]. Furthermore, chlorophyll has also been found capable of either inhibiting or reversing multi-drug resistance in the case of cancer cells and bacteria [Wang et al., 2019]. Among carotenoids, lutein is the main representative of xanthophylls, found in the leaves of higher plants [Murkovic et al., 2000; Perry et al., 2009]. The presence of carotenoids in leaf chloroplasts is associated with their function of transferring energy to chlorophylls. In addition, carotenoids neutralize free radicals formed under conditions of excessive exposure, thus protecting the entire photosynthetic apparatus of the plant. In an analogous way, lutein and zeaxanthin perform their functions also in the human body [Krinsky et al., 2003]. In addition to antiradical activity, lutein also plays a key role in the visual process. Various studies have confirmed that lutein and zeaxanthin, present in high concentrations in the macula of the eye (even 1000 times higher than in blood plasma [Hammond, 2008]), prevent the agerelated development of cataracts and macular degeneration (AMD) [Krinsky et al., 2003]. Therefore, it is generally recommended to consume large amounts of lutein-containing products to prevent the development of cataracts and AMD. Based on the scientific literature [Rodriguez-Amaya, 2016], it can be stated that among the commercial leafy vegetables, the best sources of lutein include (in a descending order): basil, parsley, spinach, coriander, kale, rocket, and chicory.

Drying is the most common way of preserving herb leaves ensuring their microbial safety and long shelf-life [Boggia et al., 2015; Chong et al., 2021]. Pre-treatments applied prior to the drying of vegetables are generally aimed at reducing processing times and therefore decreasing the processing cost due to the lower energy consumption. Thermal treatments, such as blanching or steaming, can also reduce microbial load, inhibit enzymes, and enhance the extraction of components. However, even if they exert the aforementioned benefits, the use of high temperatures may decrease the nutritional value of herbs and cause undesirable color changes and degradation of heatsensitive compounds. For this reason, the interest in non-thermal pre-processing of raw material before drying has increased in recent years, especially in relation to raw materials containing thermolabile compounds [Kaiser et al., 2013; Xiao et al., 2017].

Among different non-thermal technologies, ultrasound (US) treatment has gained particular attention, especially due to the uncomplicated construction of devices. From a physical point of view, US is a form of energy transmitted by a wave pressure, which causes vibrations of air that is inaudible to the human ear. The effects of US on biological cells depend on many factors, often related to each other. In fact, different effects are observed when US propagates in homogeneous liquids than in solid-liquid systems and two immiscible liquids [Mason et al., 2011]. Cavitation, along with compression and decompression of solid material and turbulences, especially those occurring at the interface, are very important in intensifying the heat and mass exchange during the US treatment [Dadan et al., 2021; Nowacka et al., 2021; Witrowa-Rajchert et al., 2014].

The effect of US on the content of bioactive compounds in leaves is not clear, and only a few related information can be found in the literature. The implosion of cavitation bubbles and the associated sudden and vast, although limited to a small area, changes in pressure and temperature, as well as turbulence of the medium, can activate a series of chemical transformations [Kentish \& Ashokkumar, 2011]. The generation of free radicals may lead to the degradation of antioxidants [Dadan et al., 2018]. Moreover, the structural damages to the tissue may increase the leakage of water-soluble components [Dadan et al., 2021; Gouda et al., 2021; Witrowa-Rajchert et al., 2014]. On the other hand, an increased content of some antioxidants, such as phenolics and carotenoids, and increased antioxidant capacity after US treatment were observed in various matrices, such as fresh and dried apple [Wiktor et al., 2016], carrot [Dadan \& Nowacka, 2021] as well as dried thyme [Rodriguez et al., 2013], basil [Sledz et al., 2017], parsley [Sledz et al., 2016], and mulberry leaves [Tao et al., 2016]. For this reason, US treatment is more often used to extract various compounds (e.g. phenolics, chlorophylls, essential oils, etc.) from herbal materials [Gouda et al., 2021]. Moreover, it has also been observed to increase the retention of these compouds in the dried material due to reduced drying time [Rodriguez et al., 2013].

In previous studies [Dadan et al., 2017; 2018; Sledz et al., 2017], the application of US pre-treatment has been confirmed to reduce the drying time of basil and parsley leaves and to preserve or even improve the bioactive compound content in the final products. However, chemical parameters were measured only after the drying process. The present study was therefore expected to explain the influence of a single treatment and not of both treatments (pre-treatment and drying) on herb quality. Thus, its objective was to assess the impact of different treatments (ultrasound, steaming, dipping) on the total phenolic content (TPC), antioxidant capacity, and contents of chlorophylls and lutein in basil and parsley leaves.

\section{MATERIALS AND METHODS}

\section{Material}

Basil and parsley seedlings were purchased in a garden market (Cesena, Italy). The seedlings of a similar degree of maturity were replanted and placed in a room with limited access to sunlight for 3 weeks in order to assure the homogeneity of the material. During this period, the air humidity and temperature were kept constant at the levels of $47.5 \div 50.0 \%$ and $18 \div 22^{\circ} \mathrm{C}$, respectively. Afterward, healthy and mature leaves were picked directly before the treatments. All the experiments were concluded within 1 week.

\section{Treatments: ultrasound (US), steaming (STEAM), and dipping (DIP)}

The ultrasound treatment (US) was performed by the immersive method at the frequency of $35 \mathrm{kHz}$ and the outlet power of 160 W using a water bath sonicator (TransSonic TP 690A, Elma, Singen, Germany) for 20 and $30 \mathrm{~min}$. It caused water temperature to increase to max. 8 and $11^{\circ} \mathrm{C}$ after 20 and $30 \mathrm{~min}$, respectively. Steaming (STEAM) was carried out in a single layer above boiling water $\left(99 \pm 1^{\circ} \mathrm{C}\right)$ for $3 \mathrm{~s}$. The temperature was assured by covering the material placed on a sieve with a lid. To ensure the same water/leaves contact time, after 
$3 \mathrm{~s}$ of the STEAM treatment, the leaves were kept in the water for 20 and 30 min. A metal net provided full immersion of the herbs. Dipping (DIP) in water for 20 and 30 min was used to assess the impact of immersion during the treatments. All the treatments were performed at the water temperature of $22.3 \pm 1.6^{\circ} \mathrm{C}$. For each treatment, $5.02 \pm 0.03 \mathrm{~g}$ of the herbal material on average were weighed and transferred into a beaker that was then filled with tap water. The material to water ratio was 1:40 $(w / w)$. Immediately after the treatments, the leaves were placed on a filter paper to remove excess water and then left for 15 min to assure the same conditions. Afterward, to ensure sample homogeneity, the leaves were directly frozen, then freeze-dried, and ground into powder in a grinder. The powder was then used for all chemical assays. All the treatments were repeated 3 times.

\section{Chlorophyll and lutein content}

The contents of chlorophyll a and b, and lutein were determined according to the procedure described by Guzman et al. [2012] with modifications proposed by Sledz et al. [2016]. In brief, about $0.08 \mathrm{~g}$ (the accuracy of $\pm 0.0001 \mathrm{~g}$ ) of freeze-dried material, which corresponded to approximately $0.6 \mathrm{~g}$ of fresh material, was weighed. Afterward, the pigments were extracted with acetone $80 \%\left(\mathrm{v} / \mathrm{v}, 10^{\circ} \mathrm{C}\right)$ with an addition of magnesium carbonate $(0.1 \mathrm{~g})$. The supernatant was filtered through $2 \mu \mathrm{m}$ PTFE filters. Five separate extractions were carried out for each sample.

The contents of chlorophylls and lutein in extracts were determined using a Waters ACQUITY UPLC system with a photodiode array (PDA) detector (Milford, MA, USA) and a Waters ACQUITY HSS T3 C18 column. Solvent A was a mixture of acetonitrile/methanol/chloroform (74/19/7, $v / v / v)$, and solvent B was $0.05 \%(w / v)$ ammonium acetate. The gradient elution of mobile phase was used as follows: 0-8 min - 85\% A, 15\% B; 8-9 min - eluent A from 85 to $100 \%$; 9-25 min - eluent A from 100 to $98 \%$. The settings were as follows: injection volume $-10 \mu \mathrm{L}$, injection temperature $15^{\circ} \mathrm{C}$, flow rate $-0.4 \mathrm{~mL} / \mathrm{min}$; column temperature $-35^{\circ} \mathrm{C}$, detector setting - $450 \mathrm{~nm}$ (lutein) or $650 \mathrm{~nm}$ (chlorophyll $\mathrm{a}$ and $\mathrm{b}$ ). The compounds were identified based on the retention time of external standards of chlorophyll a, chlorophyll b, and lutein (Sigma-Aldrich, Burlington, MA, USA), while their contents were computed based on the peak area in comparison to the calibration curves of the standards.

\section{Total phenolic content (TPC)}

The extraction of phenolics from basil and parsley leaf powders was carried out in three separate repetitions as described by Śledź et al. [2013]. An ethanol solution at the concentration of $80 \%(\mathrm{v} / \mathrm{v})$ was used as an extraction solvent. The mass of the powder approximated $0.21 \mathrm{~g}$ in the case of parsley and $0.06 \mathrm{~g}$ in the case of basil. Different masses of the material taken to prepare the extract resulted from different scavenging activities of the two species. The material to solvent ratio was 1:25 $(\mathrm{w} / \mathrm{v})$. The mixture was homogenized (1 $\mathrm{min}, 30,000 \mathrm{rpm}$ ), boiled (2 min), and filtered. The extracts were stored at $-18^{\circ} \mathrm{C}$ for no longer than $24 \mathrm{~h}$. After removing the extracts from frozen storage, they were equilibrated at room temperature (approx. $20^{\circ} \mathrm{C}$ ), filtered again, and subsequently used for both TPC and antioxidant capacity determinations.

The TPC was determined by the method with the Folin-Ciocalteu reagent [Singleton \& Rossi, 1965] with modifications reported previously in detail [Dadan et al., 2018]. For this purpose, water, extract, and Folin-Ciocalteu reagent (8.2, 0.3 , and $0.5 \mathrm{~mL}$, respectively) were mixed. After $3 \mathrm{~min}$, sodium carbonate was added $(1 \mathrm{~mL}, 1.7 \mathrm{M})$, and the solution was stirred again. A blank sample was prepared in an analogous way, but the extract was replaced with distilled water. After $1 \mathrm{~h}$ of storage in the dark at room temperature, the absorbance was measured at $750 \mathrm{~nm}$ against the blank sample using a Shimadzu UV-1601 spectrophotometer (Kyoto, Japan). The determination was conducted in 6 repetitions. Gallic acid (Sigma Aldrich) was used as a standard, and the calibration curve was plotted for the concentration range of 0.001$-0.020 \mathrm{mg} / \mathrm{mL}$. The results were expressed in $\mathrm{mg}$ of gallic acid equivalents per g of dry matter of plant material (mg/g d.m.).

\section{Antioxidant capacity}

Various concentrations of basil and parsley extracts (prepared as explained in Total phenolic content (TPC) section) in $80 \%(v / v)$ ethanol were used to evaluate their antiradical activity against 2,2-diphenyl-1-picrylhydrazyl (DPPH) radical (Sigma Aldrich) [Brand-Williams et al., 1995]. A constant volume of $100 \mu \mathrm{M} \mathrm{DPPH} \cdot$ solution was transferred into tubes containing the extract and ethanol, and the mixture was immediately stirred and then stored in the dark for 30 min [Dadan et al., 2018]. The absorbance was measured at $515 \mathrm{~nm}$ against 80\% ( $v / v$ ) ethanol (Shimadzu UV-1601 spectrophotometer). Because the herbal extracts absorb radiation at $515 \mathrm{~nm}$, the absorbance was measured for the extract $\left(A_{E}\right)$ without DPPH${ }^{*}$. The percentage inhibition of the radical was calculated as follows [Dadan et al., 2018]:

$$
\% \operatorname{Inh}=\frac{A_{D P P H}-A-A_{E}}{A_{D P P H}} \times 100
$$

where: \%Inh - percentage inhibition of DPPH radical; $A_{D P P H}$ - the absorbance of a control sample - a DPPH ${ }^{*}$ solution without extract; $A$ - the absorbance of the extract with a $\mathrm{DPPH}^{\cdot}$ solution; $A_{E}$ - the absorbance of extract without DPPH'.

The measurements were repeated 6 times. Afterward, the $\mathrm{EC}_{50}$ coefficient, characterizing an extract concentration required to scavenge $50 \%$ of DPPH radicals, was computed. The results were expressed in mg of dry matter of plant material per $100 \mathrm{~mL}$ of the extract $(\mathrm{mg}$ d.m./100 mL).

\section{Statistical analysis}

The significance of the differences between the analyzed results was assessed with the one-way ANOVA with Tukey's test (Statistica 12, StatSoft Polska, Cracow, Poland). The normality was checked with Shapiro-Wilk's test, whilst the homogeneity of variance with Levene's test. The significance of the influence of treatment type, time or their interactions was assessed with the two-way ANOVA with repetitions (Microsoft Excel 2013, Redmond, WA, USA). The significance level was set at 0.05 for all tests. 


\section{RESULTS AND DISCUSSION}

\section{Chlorophyll content}

Figure 1 presents the contents of chlorophyll a (high bars) and $\mathrm{b}$ (low bars) in fresh and treated basil (Figure la) and parsley (Figure 1b). In fresh basil, chlorophyll a and b contents were $11.40 \pm 0.66$ and $3.62 \pm 0.18 \mathrm{mg} / \mathrm{g}$ d.m., respectively. The total chlorophyll content reached $15.02 \pm 0.84 \mathrm{mg} / \mathrm{g} \mathrm{d.m.,} \mathrm{similarly}$ as that reported by Landi et al. [2013].

All treatments caused a significant $(\mathrm{p}<0.05)$ increase in the chlorophyll a content in basil, in comparison to fresh leaves. In turn, in the case of chlorophyll $b$, its content was statistically unchanged $(\mathrm{p} \geq 0.05)$ following different treatments. The highest content of chlorophyll a was determined in basil treated with US for $30 \mathrm{~min}$ (US $30 \mathrm{~min}$ ) and it was significantly $(\mathrm{p}<0.05)$ higher than in STEAM 20 sample. Higher extractability of, e.g., phenolics (including flavonoids), carotenoids, and essential oils, and/or better antioxidant capacity were reported in various herbal matrices as a consequence of US application [Gouda et al., 2021; Rodriguez et al., 2013; Sledz et al., 2017; Tao et al., 2016]. The authors explained that the increased extraction yield was due to the occurrence of cavitation and "sponge effect" causing cell disruption. In the present study, steaming caused no differences in the chlorophyll content in basil compared to dipping.
Kaiser at al. [2013] reported that steaming resulted in an increased release of components due to the thermal damage of cellular structure and subcellular membranes. Also, Di Cesare et al. [2003] demonstrated a higher content of chlorophyll in blanched basil after drying. It can be concluded that all treatments probably contributed to an impairment of the cells and/or membranes (e.g. thylakoid membranes of chloroplasts) in basil and then to a release of chlorophylls. In all basil samples, the contents of chlorophyll a and b were significantly affected by leaf dipping in water, which increased them irrespective of duration. Probably the dipping treatment contributed to loosening the structure and better extractability of the pigments from basil.

In the case of fresh parsley leaves (Figure 1b), lower chlorophyll contents were noted, i.e.: $6.21 \pm 0.74 \mathrm{mg} / \mathrm{g}$ d.m. for chlorophyll a, $1.48 \pm 0.21 \mathrm{mg} / \mathrm{g} \mathrm{d} . \mathrm{m}$. for chlorophyll b, and $7.69 \pm 0.94 \mathrm{mg} / \mathrm{g} \mathrm{d} . \mathrm{m}(7.45 \mathrm{mg} / \mathrm{g}$ of fresh matter, f.m.) for total chlorophyll. In turn, Akbudak \& Akbudak [2013] determined a total chlorophyll content in parsley at $2.33 \mathrm{mg} / \mathrm{g}$ (on f.m. basis). Presumably, the slight discrepancies in the obtained results were due to different varieties and growth conditions of plants or different maturation stages of leaves.

Differences in chlorophyll a and b content were not statistically significant $(\mathrm{p} \geq 0.05)$ in parsley. The observed results were opposite to those found for the treated basil, probably
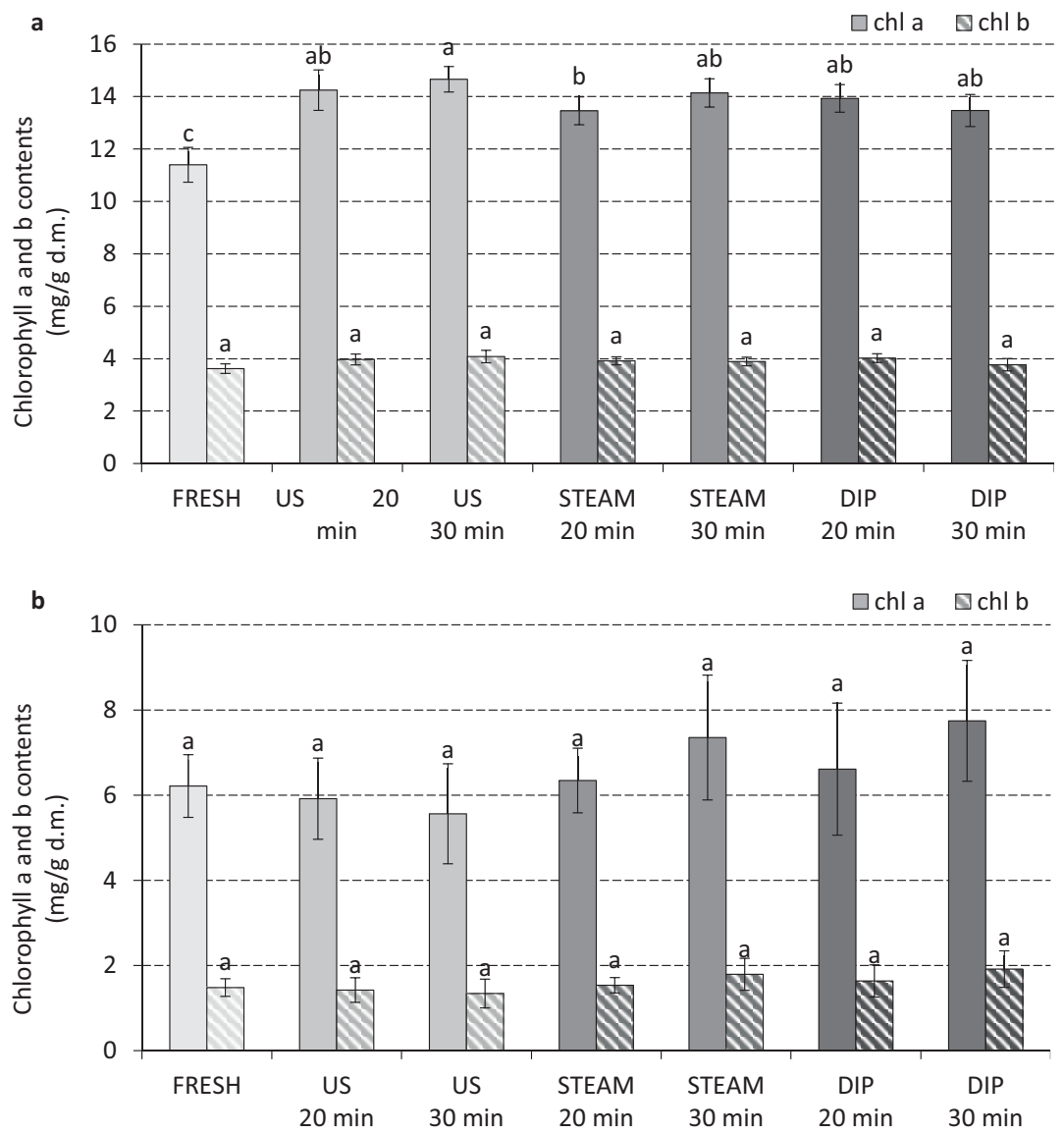

FIGURE 1. Chlorophyll a (high bars) and chlorophyll b (low bars with diagonal lines) contents of basil (a) and parsley (b) leaves: fresh and subjected to 20 or $30 \mathrm{~min}$ of the following treatments: US - ultrasound; STEAM - steaming followed by dipping; and DIP - dipping. 
because of the different thickness of epidermis (the layer of cells on the leaves devoid of chlorophylls) between the two species. Parsley is characterized by a high turgor and stiffness of leaves and therefore presented a high stability of green pigments, while basil is more "sensitive" to soaking, which resulted in a higher "relaxation" of external structures after the applied treatments and possible impact on the internal structures containing chloroplasts.

Chlorophyll a imparts blue-green color, while chlorophyll $b$ is more yellow-green. In higher plants, chlorophyll a is present in higher concentration than the $b$ form. Because two types of chlorophyll can be degraded to a different extent during various processing treatments [Di Cesare et al., 2003; Rodriguez-Amaya, 2019], maintaining the ratio of the contents of chlorophyll a and chlorophyll b $(\mathrm{Chl} \mathrm{a/Chl} \mathrm{b)} \mathrm{as} \mathrm{close}$ as possible to the level in fresh plant guarantees a stable, natural color of dried herbs. The $\mathrm{Chl} \mathrm{a/Chl} \mathrm{b} \mathrm{ratios} \mathrm{in} \mathrm{fresh}$ and treated basil and parsley leaves are presented in Figure $2 \mathrm{a}$ and Figure $2 \mathrm{~b}$, respectively. The $\mathrm{Chl} \mathrm{a} / \mathrm{Chl} \mathrm{b}$ ratio varied from $3.15 \pm 0.04$ (FRESH) to $3.64 \pm 0.05$ (STEAM $30 \mathrm{~min}$ ) for basil, as well as from $4.04 \pm 0.04$ (DIP $20 \mathrm{~min}$ ) to $4.21 \pm 0.11$ (FRESH) for parsley. These values were consistent with those shown in the literature; Di Cesare et al. [2003] found that chlorophyll a content in basil leaves was 2.5-3 times higher than that of chlorophyll b. In the current study, a higher content of chlorophyll a following different treatments of basil samples resulted in a significant increase in the $\mathrm{Chl}$ a/ Chl b ratio (by 9-16\%) in comparison to the fresh material. The highest value of the ratio was observed when basil was subjected to STEAM $30 \mathrm{~min}$; however, the values did not significantly ( $\mathrm{p} \geq 0.05)$ differ compared to those obtained by other treatments for $30 \mathrm{~min}$ and US treatment for $20 \mathrm{~min}$. The last sample showed the $\mathrm{Chl} \mathrm{a/Chl} \mathrm{b}$ ratio significantly $(\mathrm{p}<0.05)$ higher in comparison to the samples obtained by other treatments for the same treatment time $(20 \mathrm{~min})$. It was proven that the duration of basil processing had a significant impact on the $\mathrm{Chl} \mathrm{a} / \mathrm{Chl} \mathrm{b}$ ratio $(\mathrm{p}=0.0003)$. Furthermore, also the interaction of treatment duration and type was statistically relevant ( $\mathrm{p}=0.0057)$, whereas the treatment type did not have a significant influence $(\mathrm{p} \geq 0.05)$. Concerning parsley leaves, the applied treatments did not affect the $\mathrm{Chl} \mathrm{a/Chl} \mathrm{b} \mathrm{ratio.}$ The significance of treatment duration and type and the interaction of both these factors was not confirmed ( $\mathrm{p} \geq 0.05)$.

The obtained results did not confirm literature data indicating degradation of chlorophylls as a consequence of blanching [Oliveira et al., 2016], and of reactive oxygen species formed during sonication [Kentish \& Ashokkumar, 2011]. Probably, a different mechanism of degradation (not thermal as the blanching was relatively short) as well as enhanced extraction of chlorophylls occurred. What is more, the study
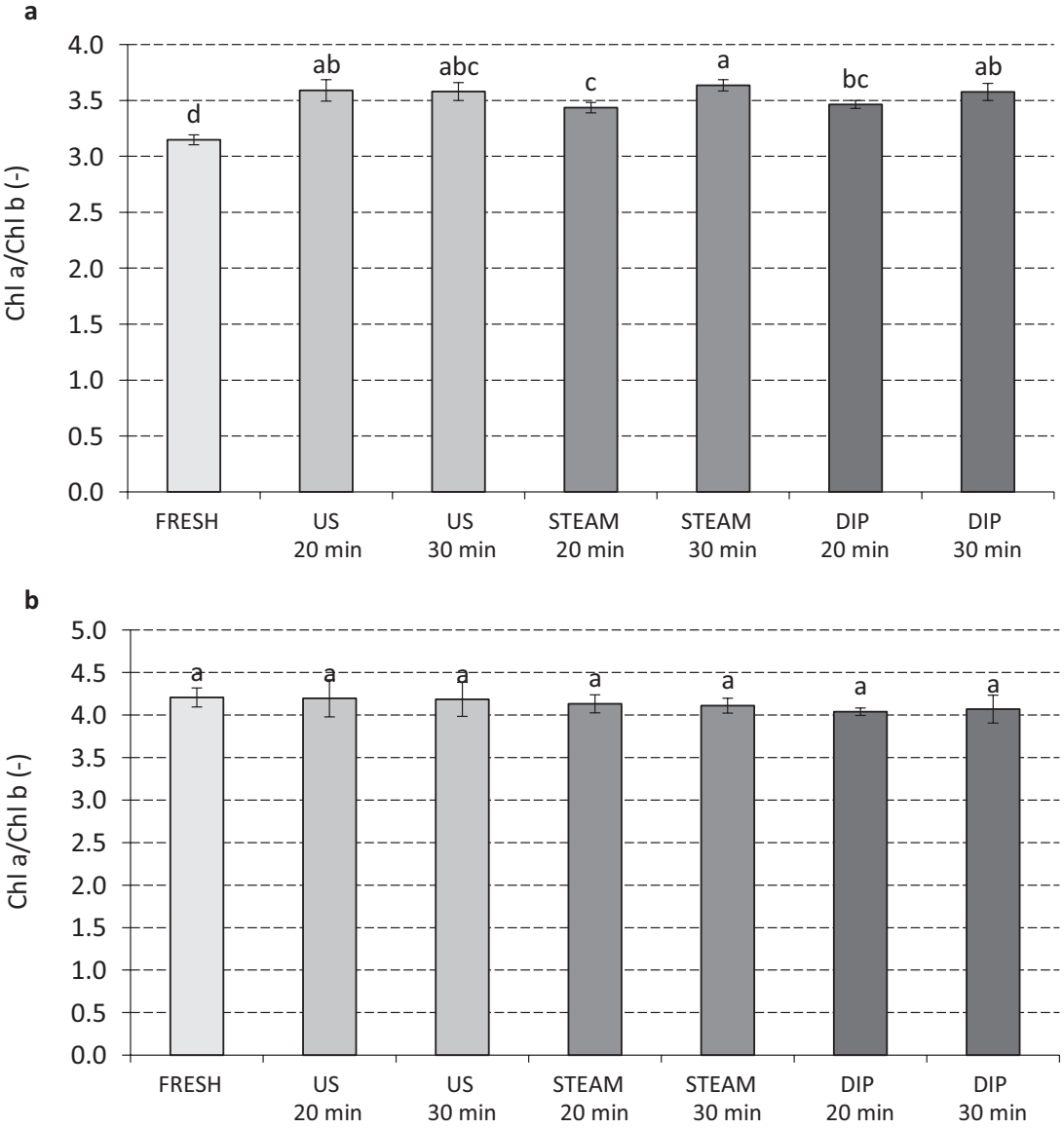

FIGURE 2. Chlorophyll a to chlorophyll b ratio ( $\mathrm{Chl} \mathrm{a/Chl} \mathrm{b)} \mathrm{in} \mathrm{basil} \mathrm{(a)} \mathrm{and} \mathrm{parsley} \mathrm{(b)} \mathrm{leaves:} \mathrm{fresh} \mathrm{and} \mathrm{subjected} \mathrm{to} 20$ or 30 min of the following treatments: US - ultrasound; STEAM - steaming followed by dipping; and DIP - dipping. 
proved the benefits of applying treatments in the case of basil and no contraindications of their use for parsley, giving therefore many reasons to promote the possibility of implementing additional treatments before, e.g., drying or freezing, which cause no adverse changes in the material.

\section{Lutein content}

The lutein content in fresh and treated basil and parsley leaves is presented in Figures $3 \mathrm{a}$ and $3 \mathrm{~b}$, respectively. Both species showed to be a good source of lutein, with contents of $92.3 \pm 4.8 \mathrm{mg} / 100 \mathrm{~g} \mathrm{~d} . \mathrm{m}$. in fresh basil and $41.3 \pm 5.3 \mathrm{mg} / 100 \mathrm{~g} \mathrm{~d} . \mathrm{m}$. in fresh parsley, which corresponded to a content of $6.73 \pm 0.35$ and $6.18 \pm 0.79$ $\mathrm{mg} / 100 \mathrm{~g}$ f.m., respectively. Similar results were obtained by Murkovic et al. [2000], who reported that the sum of lutein and zeaxanthin amounted to $7.05 \mathrm{mg} / 100 \mathrm{~g}$ f.m. in basil and $6.4 \mathrm{mg} / 100 \mathrm{~g}$ f.m. in parsley. Also, Daly et al. [2010] determined a higher content of lutein and zeaxanthin in basil than in parsley. Moreover, Perry et al. [2009] have stated that green leafy vegetables are the best sources of lutein, in comparison to other vegetables and fruits. However, Dadan et al. [2018] found a higher content of lutein in dried parsley leaves (81.1-130.6 mg/100 g d.m.), which was probably due to using different varieties of parsley and/or plants growing under different climate and soil conditions.

The lutein content in the material subjected to the different treatments was stable and did not show any statistical difference $(\mathrm{p} \geq 0.05)$ in both basil (Figure 3a) and parsley (Figure 3b). In fact, based on the analysis of the influence of treatment type and duration, it can be concluded that none of the factors significantly differentiated the content of lutein in both species $(\mathrm{p} \geq 0.05)$. Similar observations were reported in our previous studies in dried parsley [Dadan et al., 2018; Sledz et al., 2016], confirming the high stability of lutein during treatments. As reported by Perry et al. [2009], carotenoids in leaves are responsible for the protection of chlorophylls from external factors. Hence, the stability of lutein inhibited chlorophyll degradation. It is also possible that, as a result of structure softening, the susceptibility of lutein to the extraction increased, which "camouflaged" its degradation.

\section{Total phenolic content (TPC)}

Herbs are excellent sources of antioxidants, among which phenolics are the main represented group. The total phenolic content (TPC) in fresh and differently treated (US-treated, steamed or dipped) basil is shown in Figure 4a. A TPC of fresh basil was $37.7 \pm 1.3 \mathrm{mg} / \mathrm{g} \mathrm{d}$.m. This value obtained for the basil cultivated in Italy (current study) was slightly higher than those obtained for basil cultivated in Israel [Hossain et al., 2010] and Poland [Sledz et al., 2013], amounting to 20 and $29.74 \mathrm{mg} / \mathrm{g}$ d.m., respectively. This could probably be due to the differences in the variety and climate conditions during plant growth. Figure $4 \mathrm{a}$ shows that both treatment type and duration influenced the TPC in basil. In general,

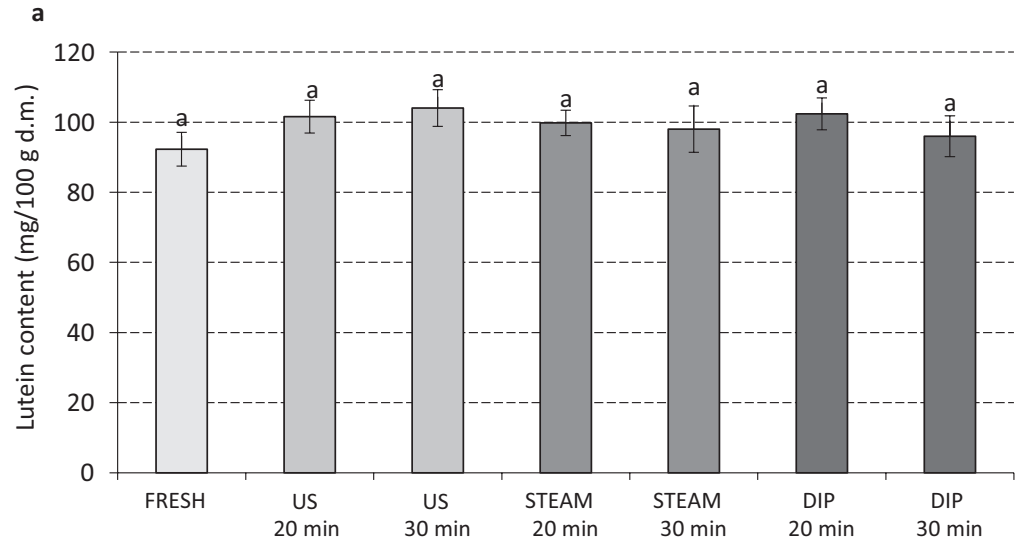

b

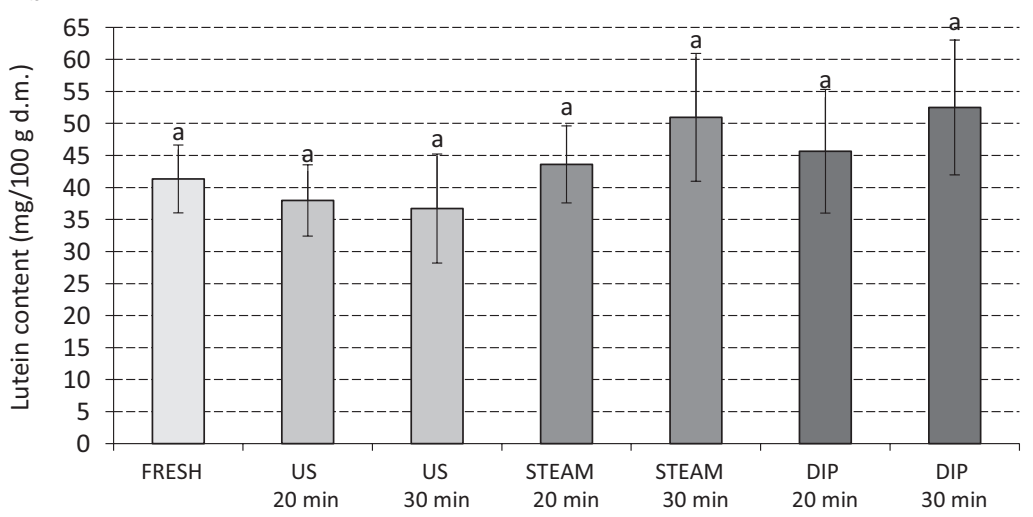

FIGURE 3. Lutein content of basil (a) and parsley (b) leaves: fresh and subjected to 20 or 30 min of the following treatments: US - ultrasound; STEAM - steaming followed by dipping; and DIP - dipping. 
with treatment time extension, a significantly $(\mathrm{p}<0.05)$ lower TPC was determined in basil, regardless of treatment type.

The highest TPC was noted in DIP 20 min basil sample. This could be a result of water stress, which promotes the activation of basil defence mechanism, causing an additional synthesis of phenolics [Mazzeo et al., 2011]. That kind of beneficial response to mild stress and degradation as a result of high stress is generally known as hormetic effect [Kouda \& Iki, 2010]. A longer dipping time resulted in the leaching of these "released" substances into the liquid medium during treatment. However, the TPC of DIP $30 \mathrm{~min}$ sample was at the same level as in the fresh leaves. The samples treated by ultrasound and steam for 20 min showed statistically $(\mathrm{p} \geq 0.05)$ unchanged TPC in comparison to the fresh one. However, these values were lower than in the samples just dipped in water (DIP $20 \mathrm{~min}$ ), as also observed by Chemat et al. [2011]. The total content of phenolics may stem from different opposite phenomena. An increased content might be observed due to water stress and increased extraction [Wiktor et al., 2016]. In turn, a decrease can be caused by degradation due to free radicals generated during sonication [Kentish \& Ashokkumar, 2011] or leakage of intracellular phenolic compounds and release of oxidative enzymes upon mechanical stress caused by US [Santacatalina et al., 2014]. To better understand the observed differences, a complete characterization of the phenolic profile is probably necessary. Instead, steaming could promote damage to basil leaf layers caused by fast delivery of the thermal power during the treatment and, therefore, the leakage of phenolics into the water. In fact, the lowest content of phenolics was determined in basil samples subjected to the soaking in water for $30 \mathrm{~min}$ after steaming (Figure 4a). Mazzeo et al. [2011] found an increase in the phenolic content in spinach steam-blanched for $20 \mathrm{~min}$; however, they did not perform a dipping in water after blanching. It is worth noticing that in the current research, the material dipped in water for similar periods but not subjected to steaming was always characterized by a higher TPC than the samples subjected to steaming, concluding that the use of steam was not a beneficial treatment for basil.

A different effect of the applied treatments on the TPC was observed in parsley leaves (Figure 4b). In fresh parsley, the TPC was $25.4 \pm 0.5 \mathrm{mg} / \mathrm{g}$ d.m., which was $33 \%$ lower than in basil (Figure 4a). All the treatments caused a significant $(\mathrm{p}<0.05)$ decrease in TPC compared to the fresh parsley leaves. The lowest TPC was determined in the samples treated with US for $20 \mathrm{~min}$ and dipped. However, extending US treatment time from 20 to 30 min increased the TPC, probably due to the fact that $30 \mathrm{~min}$ was a threshold to observe a hormetic effect in parsley, as it was explained above. Ince et al. [2014] found that US treatment did not enhance phenolic extraction in nettle compared with the conventional extraction method. Therefore, a different response of basil and parsley leaves to the US treatment could probably be related to the differences in the tissue structure, such as thickness of the skin, the cell
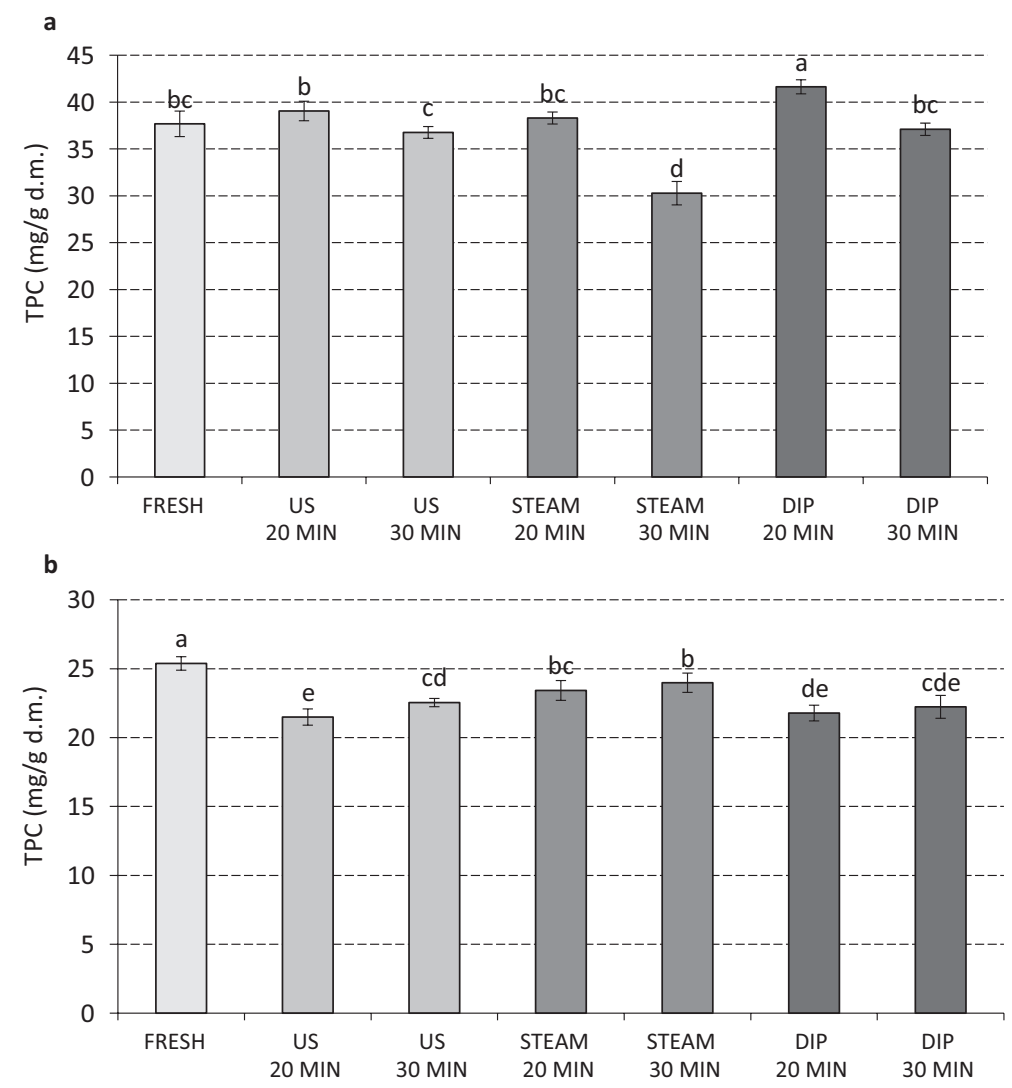

FIGURE 4. Total phenolic content (TPC) of basil (a) and parsley (b) leaves: fresh and subjected to 20 or 30 min of the following treatments: US - ultrasound; STEAM - steaming followed by dipping; and DIP - dipping. 
turgor, and leaf "stiffness". Furthermore, the different changes observed in the content of chlorophylls and TPC after the applied treatment could also be due to the different location of considered compounds inside the cells. Phenolics are located inside the vacuoles, while chlorophylls inside the chloroplast [Mannozzi et al., 2018]. In general, US can damage cell membranes and walls, contributing to a greater degree of phenolic extraction from the tissue [Wiktor et al., 2016]. Perhaps this increased efficiency of extraction in parsley leaves was "camouflaged" by degradation of phenolics, as a result of the formation of reactive oxygen species or enhanced activity of enzymes, such as polyphenol oxidase, released from tissues [Kentish \& Ashokkumar, 2011]. Among the treated parsley samples, the highest TPC was in those treated by steaming, even though it was significantly lower in comparison to the fresh leaves (Figure 4b). The highest retention of phenolics in a thermally-processed material may be related to the hormetic effect or removal of air from the cells [Oliveira et al., 2016].

\section{Antioxidant capacity}

The $\mathrm{EC}_{50}$ value, which indicates the concentration of the extract necessary to scavenge half of the initial DPPH radicals, of fresh basil was $7.50 \pm 0.24 \mathrm{mg} \mathrm{d.m./100} \mathrm{mL} \mathrm{(Figure} \mathrm{5a).} \mathrm{For}$ fresh parsley instead, a value of $67.0 \pm 6.5 \mathrm{mg} \mathrm{d} . \mathrm{m} . / 100 \mathrm{~mL}$ was determined (Figure 5b), which means that the antioxidant capacity of basil was 9 times higher than that of parsley.
It is worth noting that the TPC in parsley was also lower than in basil, but only 1.5 times (Figures $4 \mathrm{a}$ and $4 \mathrm{~b}$ ). It can be assumed that the differences in antioxidant capacity could be due to the different composition of phenolic compounds in both species, which requires further studies.

Concerning basil leaves, the results in Figure $5 \mathrm{a}$ indicate that antioxidant capacity of all samples treated for $20 \mathrm{~min}$ did not show any significant ( $\mathrm{p} \geq 0.05)$ differences in comparison to the fresh leaves. However, an extension of the treatment time till 30 min resulted in a significant $(\mathrm{p}<0.05)$ reduction of antioxidant capacity (an increase of the $\mathrm{EC}_{50}$ ). In the case of fresh basil, the $\mathrm{EC}_{50}$ was higher in the samples following different treatments by 30\% (US $30 \mathrm{~min}$ ), 54\% (STEAM $30 \mathrm{~min}$ ), and $32 \%$ (DIP $30 \mathrm{~min}$ ). These results do not match neither the data of lutein content nor TPC. However, as stated above, since various phenolics might exert different antioxidant activities, a complete characterization of the phenolic profile might give some insight to the observed differences. Based on the two-way ANOVA, it was noticed that the treatment duration had the greatest impact on basil antiradical activity against $\mathrm{DPPH}^{\circ}$. The type of treatment and the interaction of both factors also significantly $(\mathrm{p}<0.05)$ differentiated $\mathrm{EC}_{50}$ values, but to a lesser extent. Wiktor et al. [2016] showed that with an elongation of sonication $(40 \mathrm{kHz})$ time, the content of polyphenols in apple significantly decreased, which was not translated into a statistically significant increase

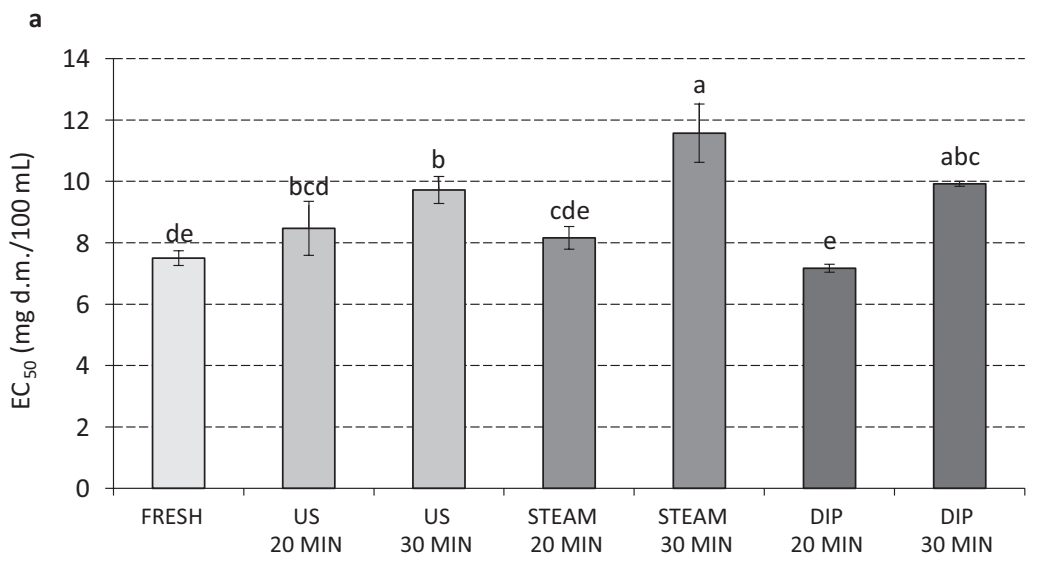

b

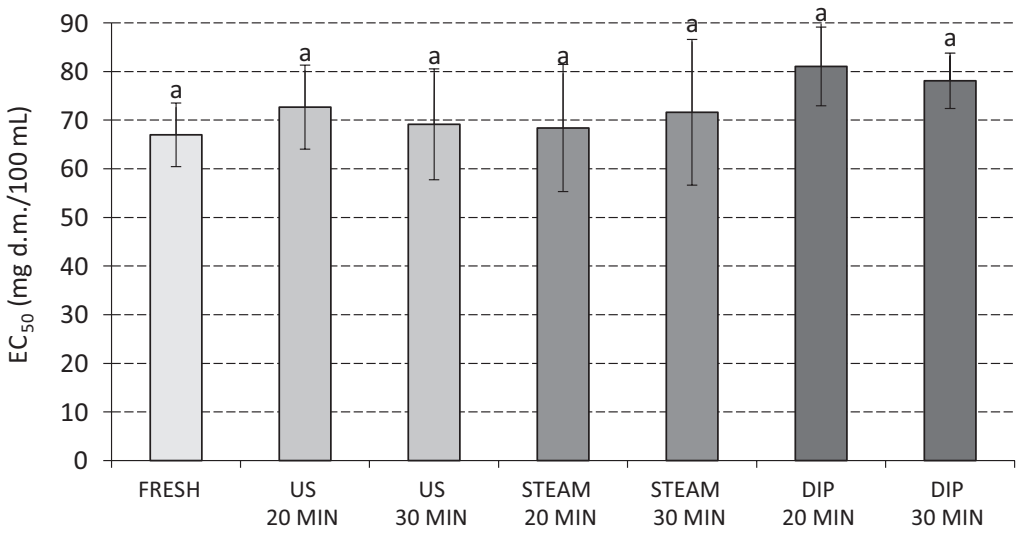

FIGURE 5. $\mathrm{EC}_{50}$ of DPPH ${ }^{*}$ scavenging activity of basil (a) and parsley (b) leaves: fresh and subjected to 20 or 30 min of the following treatments: US - ultrasound; STEAM - steaming followed by dipping; and DIP - dipping. 
of the $\mathrm{EC}_{50}$. On the other hand, antioxidant capacity and TPC did not differ significantly between the treatments carried out from 5 to $30 \mathrm{~min}$ at a frequency of $21 \mathrm{kHz}$.

Concerning the results of the antioxidant capacity of parsley, no significant $(\mathrm{p} \geq 0.05)$ differences in the $\mathrm{EC}_{50}$ were observed in the fresh material and those subjected to the different treatments (Figure 5b). Moreover, the effects of treatment type and duration on the DPPH ${ }^{*}$ scavenging activity of parsley extracts were not significant $(\mathrm{p} \geq 0.05)$. The various extent of changes observed in the scavenging ability against DPPH ${ }^{*}$ in the case of basil and parsley could be due to the different anatomical and morphological structure of their leaves.

\section{CONCLUSIONS}

The study revealed that basil contained a higher amount of all the investigated bioactive compounds (chlorophylls, lutein, and total phenolics), and exhibited a higher antioxidant capacity, in comparison to parsley. It was also characterized by greater changes as a consequence of US treatment, steaming and dipping, presumably due to a different thickness of epidermis layer. In basil, all the treatments promoted an increase of the chlorophyll a content, while TPC increased only after 20 min of dipping and was reduced by steaming for $30 \mathrm{~min}$. Parsley subjected to treatments was characterized by a stable content of chlorophylls but by a lower content of total phenolics. Lutein remained stable in both herbs regardless of treatment type. Finally, the antioxidant capacity was reduced after $30 \mathrm{~min}$ of all treatments in basil, while remained stable in parsley.

The obtained results demonstrated that the ultrasound, steaming or dipping treatments only slightly affected the quality of herbal leaves. Considering our previously reported data [Dadan et al., 2017; Sledz et al., 2017, 2016] showing that ultrasound and steaming reduced the drying time of basil and parsley, while US additionally reduced the total energy consumption [Dadan et al., 2017], the sonication is recommended as a pre-treatment before drying in the case of both species.

\section{ACKNOWLEDGEMENTS}

The authors wish to thank to Prof. Malgorzata Nowacka for proof-reading the manuscript.

\section{RESEARCH FUNDING}

This study was supported by a statutory activity subsidy from the Polish Ministry of Science and Higher Education for the Faculty of Food Sciences of Warsaw University of Life Sciences.

\section{CONFLICT OF INTERESTS}

The authors declare that they have no conflict of interest.

\section{ORCIDS IDs}

M. Dadan https://orcid.org/0000-0001-7647-0592

M. Dalla Rosa https://orcid.org/0000-0002-0405-7026

K. Rybak https://orcid.org/0000-0003-3595-0818
S. Tappi https://orcid.org/0000-0003-0711-859X

U. Tylewicz https://orcid.org/0000-0002-8192-6803

D. Witrowa-Rajchert https://orcid.org/0000-0002-0937-3204

\section{REFERENCES}

1. Ahmed, A.F., Attia, F.A.K., Liu, Z., Li, C., Wei, J., Kang, W. (2019). Antioxidant activity and total phenolic content of essential oils and extracts of sweet basil (Ocimum basilicum L.) plants. Food Science and Human Wellness, 8(3), 299-305.

https://doi.org/10.1016/j.fshw.2019.07.004

2. Akbudak, N., Akbudak, B. (2013). Effect of vacuum, microwave, and convective drying on selected parsley quality. International Journal of Food Properties, 16(1), 205-215. https://doi.org/10.1080/10942912.2010.535400

3. Boggia, R., Zunin, P., Hysenaj, V., Bottino, A., Comite, A. (2015). Dehydration of basil leaves and impact of processing composition. In V. Preedy (Ed.), Processing and Impact on Active Components in Food, Chapter 78, Elsevier Inc., London, pp. 645-653. https://doi.org/10.1016/B978-0-12-404699-3.00078-0

4. Brand-Williams, W., Cuvelier, M.E., Berset, C. (1995). Use of a free radical method to evaluate antioxidant activity. $L W T-$ Food Science and Technology, 28(1), 25-30.

https://doi.org/10.1016/S0023-6438(95)80008-5

5. Charles, D.J. (2012). Parsley. In K.V. Peter (Ed.), Handbook of Herbs and Spices, vol. 1, Se, Woodhead Publishing Limited, Cambridge, pp. 430-451.

https://doi.org/10.1533/9780857095671.430

6. Chemat, F., Zill-e-Huma, Khan, M.K. (2011). Applications of ultrasound in food technology: Processing, preservation and extraction. Ultrasonics Sonochemistry, 18(4), 813-835. https://doi.org/10.1016/j.ultsonch.2010.11.023

7. Chong, C.H., Figiel, A., Szummy, A., Wojdyło, A., Chua, B.L., Khek, C.H., Yuan, M.C. (2021). Herbs drying. In Ch.M. Galankis (Ed.), Aromatic herbs in food. Bioactive compounds, processing, and applications, Chapter 5, Academic Press, pp. 167-200. https://doi.org/10.1016/B978-0-12-822716-9.00005-6

8. Dadan, M., Nowacka, M. (2021). The assessment of the possibility of using ethanol and ultrasound to design the properties of dried carrot tissue. Applied Sciences (Switzerland), 11(2), art. no. 689 .

https://doi.org/10.3390/app11020689

9. Dadan, M., Nowacka, M., Rybak, K., Wiktor, A., Witrowa-Rajchert, D. (2017). An optimisation of microwave-convective drying of parsley leaves subjected to ultrasound and steaming treatments, carried out on the basis of the response surface methodology. Zeszyty Problemowe Postępów Nauk Rolniczych, 589, 15-25 (in Polish; English abstract).

https://doi.org/10.22630/ZPPNR.2017.589.17

10. Dadan, M., Nowacka, M., Wiktor, A., Sobczynska, A., Witrowa-Rajchert, D. (2021). Ultrasound to improve drying processes and prevent thermolabile nutrients degradation. In F.J. Barba, G. Cravotto, F. Chemat, J.M. Lorenzo Rodriguez, P.E.S. Munekata (Eds.), Design and Optimization of Innovative Food Processing Techniques Assisted by Ultrasound, Academic Press, London, pp. 55-110. https://doi.org/10.1016/B978-0-12-818275-8.00010-6

11. Dadan, M., Rybak, K., Wiktor, A., Nowacka, M., Zubernik, J., Witrowa-Rajchert, D. (2018). Selected chemical composition 
changes in microwave-convective dried parsley leaves affected by ultrasound and steaming pre-treatments - An optimization approach. Food Chemistry, 239, 242-251.

https://doi.org/10.1016/j.foodchem.2017.06.061

12. Daly, T., Jiwan, M.A., O'Brien, N.M., Aherne, S.A. (2010). Carotenoid content of commonly consumed herbs and assessment of their bioaccessibility using an in vitro digestion model. Plant Foods for Human Nutrition, 65, 164-169. https://doi.org/10.1007/s11130-010-0167-3

13. Di Cesare, L.F., Forni, E., Viscardi, D., Nani, R.C. (2003). Changes in the chemical composition of basil caused by different drying procedures. Journal of Agricultural and Food Chemistry, 51(12), 3575-3581.

https://doi.org/10.1021/jf021080o

14. Gouda, M., Bekhit, A.E., Tang, Y., Huang, Y., Huang, L., He, Y., Li, X. (2021). Recent innovations of ultrasound green technology in herbal phytochemistry: A review. Ultrasonics Sonochemistry, 73, art. no. 105538 .

https://doi.org/10.1016/j.ultsonch.2021.105538

15. Guzman, I., Yousef, G.G., Brown, A.F. (2012). Simultaneous extraction and quantitation of carotenoids, chlorophylls, and tocopherols in Brassica vegetables. Journal of Agricultural and Food Chemistry, 60(29), 7238-7244.

https://doi.org/10.1021/jf302475d

16. Hammond, B.R. (2008). Possible role for dietary lutein and zeaxanthin in visual development. Nutrition Reviews, 66(12), 695-702. https://doi.org/10.1111/j.1753-4887.2008.00121.x

17. Hossain, M.B., Barry-Ryan, C., Martin-Diana, A.B., Brunton, N.P. (2010). Effect of drying method on the antioxidant capacity of six Lamiaceae herbs. Food Chemistry, 123(1), 85-91. https://doi.org/10.1016/j.foodchem.2010.04.003

18. Ince, A.E., Sahin, S., Sumnu, G. (2014). Comparison of microwave and ultrasound-assisted extraction techniques for leaching of phenolic compounds from nettle. Journal of Food Science and Technology, 51(10), 2776-2782.

https://doi.org/10.1007/s13197-012-0828-3

19. Kaiser, A., Carle, R., Kammerer, D.R. (2013). Effects of blanching on polyphenol stability of innovative paste-like parsley (Petroselinum crispum (Mill.) Nym ex A. W. Hill) and marjoram (Origanum majorana L.) products. Food Chemistry, 138(2-3), 1648-1656.

https://doi.org/10.1016/j.foodchem.2012.11.063

20. Kentish, S., Ashokkumar, M. (2011). The physical and chemical effect of ultrasound. In H. Feng, G.V. Barosa-Canovas, J. Weiss (Eds.), Ultrasound Technologies for Food and Bioprocessing, LLC, New York, pp. 1-12.

https://doi.org/10.1007/978-1-4419-7472-3_1

21. Kopsell, D.A., Kopsell, D.E. (2006). Accumulation and bioavailability of dietary carotenoids in vegetable crops. Trends in Plant Science, 11(10), 499-507.

https://doi.org/10.1016/j.tplants.2006.08.006

22. Kouda, K., Iki, M. (2010). Beneficial effects of mild stress (hormetic effects): dietary restriction and health. Journal of Physiological Anthropology, 29(4), 127-132.

https://doi.org/10.2114/jpa2.29.127

23. Krinsky, N.I., Landrum, J.T., Bone, R.A. (2003). Biologic mechanisms of the protective role of lutein and zeaxanthin in the eye. Annual Review of Nutrition, 23(1), 171-201.

https://doi.org/10.1146/annurev.nutr.23.011702.073307
24. Kurian, A. (2012). Health benefits of herbs and spices. In K.V. Peter (Ed.), Handbook of Herbs and Spices, vol. 2, Se, Woodhead Publishing Limited, Cambridge, pp. 72-88. https://doi.org/10.1533/9780857095688.72

25. Landi, M., Pardossi, A., Remorini, D., Guidi, L. (2013). Antioxidant and photosynthetic response of a purple-leaved and a green-leaved cultivar of sweet basil (Ocimum basilicum) to boron excess. Environmental and Experimental Botany, 85, 64-75. https://doi.org/10.1016/j.envexpbot.2012.08.008

26. Liberal, Â., Fernandes, Â., Polyzos, N., Petropoulos, S.A., Dias, M.I., Pinela, J., Petrović, J., Soković, M., Ferreira, I.C.F.R, Barros, L. (2020). Bioactive properties and phenolic compound profiles of turnip-rooted, plain-leafed and curly-leafed parsley cultivars. Molecules, 25(23), art no. 5606.

https://doi.org/10.3390/molecules25235606

27. Mannozzi, C., Fauster, T., Haas, K., Tylewicz, U., Romani, S., Dalla Rosa, M., Jaeger, H. (2018). Role of thermal and electric field effects during the pre-treatment of fruit and vegetable mash by pulsed electric fields (PEF) and ohmic heating $(\mathrm{OH})$. Innovative Food Science \& Emerging Technologies, 48, 131-137. https://doi.org/10.1016/j.ifset.2018.06.004

28. Mason, T.J., Paniwnyk, L., Chemat, F., Vian, M.A. (2011). Chapter 10. Ultrasonic Food Processing. In A. Proctor (Ed.), Alternatives to Conventional Food Processing, Royal Society of Chemistry, Cambridge, pp. 387-414.

https://doi.org/10.1039/9781849730976-00387

29. Mazzeo, T., N'Dri, D., Chiavaro, E., Visconti, A., Fogliano, V., Pellegrini, N. (2011). Effect of two cooking procedures on phytochemical compounds, total antioxidant capacity and colour of selected frozen vegetables. Food Chemistry, 128(3), 627-633. https://doi.org/10.1016/j.foodchem.2011.03.070

30. Murkovic, M., Gams, K., Draxl, S., Pfannhauser, W. (2000). Development of an Austrian Carotenoid Database. Journal of Food Composition and Analysis, 13(4), 435-440.

https://doi.org/10.1006/jfca.2000.0909

31. Nowacka, M., Dadan, M., Tylewicz, U. (2021). Current applications of ultrasound in fruit and vegetables osmotic dehydration processes. Applied Sciences (Switzerland), 11(3), art. no. 1269. https://doi.org/10.3390/app11031269

32. Oliveira, S.M., Brandão, T.R.S., Silva, C.L.M. (2016). Influence of drying processes and pretreatments on nutritional and bioactive characteristics of dried vegetables: A review. Food Engineering Reviews, 8(2), 134-163.

https://doi.org/10.1007/s12393-015-9124-0

33. Pérez-Gálvez, A., Viera, I., Roca, M. (2020). Carotenoids and chlorophylls as antioxidants. Antioxidants, 9(6), art. no. 505. https://doi.org/10.3390/antiox9060505

34. Perry, A., Rasmussen, H., Johnson, E.J. (2009). Xanthophyll (lutein, zeaxanthin) content in fruits, vegetables and corn and egg products. Journal of Food Composition and Analysis, 22(1), 9-15. https://doi.org/10.1016/j.jfca.2008.07.006

35. Peter, K.V. (2012). Introduction to herbs and spices: medicinal uses and sustainable production. In K.V. Peter (Ed.), Handbook of Herbs and Spices, vol. 2, Se, Woodhead Publishing Limited, Cambridge, pp. 1-16. https://doi.org/10.1533/9780857095688.1

36. Rodriguez-Amaya, D.B. (2016). Chapter 5. Composition and influencing factors. In Food Carotenoids: Chemistry, Biology and Technology, John Wiley \& Sons Ltd., Oxford, pp. 96-131. https://doi.org/10.1002/9781118864364.ch5 
37. Rodriguez-Amaya, D.B. (2019). Natural food pigments and colorants. In J.-M. Mérillon, K.G. Ramawat (Eds.), Bioactive Molecules in Food, Springer, Cham., pp. 867-901.

https://doi.org/10.1007/978-3-319-78030-6_12

38. Rodriguez, J., Melo, E.C., Mulet, A., Bon, J. (2013). Optimization of the antioxidant capacity of thyme (Thymus vulgaris L.) extracts: Management of the convective drying process assisted by power ultrasound. Journal of Food Engineering, 119(4), 793-799. https://doi.org/10.1016/j.jfoodeng.2013.07.016

39. Santacatalina, J.V., Rodríguez, O., Simal, S., Cárcel, J.A., Mulet, A., García-Pérez, J.V. (2014). Ultrasonically enhanced low-temperature drying of apple: Influence on drying kinetics and antioxidant potential. Journal of Food Engineering, 138, 35-44.

https://doi.org/10.1016/j.jfoodeng.2014.04.00

40. Singleton, V.L., Rossi, J.A. (1965). Colorimetry of total phenolic with phosphomolibdic-phosphotungstic acid reagents. American Journal of Enology and Viticulture, (16), 144-158.

41. Śledź, M., Nowacka, M., Wiktor, A., Witrowa-Rajchert, D. (2013). Selected chemical and physico-chemical properties of microwave-convective dried herbs. Food and Bioproducts Processing, 91(4), 421-428.

https://doi.org/10.1016/j.fbp.2013.02.010

42. Sledz, M., Wiktor, A., Nowacka, M., Witrowa-Rajchert, D. (2017). Drying kinetics, microstructure and antioxidant properties of basil treated by ultrasound. Journal of Food Process Engineering, 40(1), art. no. e12271.

https://doi.org/10.1111/jfpe.12271

43. Sledz, M., Wiktor, A., Rybak, K., Nowacka, M., Witrowa-Rajchert, D. (2016). The impact of ultrasound and steam blanching pre- treatments on the drying kinetics, energy consumption and selected properties of parsley leaves. Applied Acoustics, 103 Part B, 148-156. https://doi.org/10.1016/j.apacoust.2015.05.006

44. Tao, Y., Wang, P., Wang, Y., Kadam, S.U., Han, Y., Wang, J., Zhou, J. (2016). Power ultrasound as a pretreatment to convective drying of mulberry (Morus alba L.) leaves: Impact on drying kinetics and selected quality properties. Ultrasonics Sonochemistry, 31, 310-318 https://doi.org/10.1016/j.ultsonch.2016.01.012

45. Wang, E., Braun, M.S., Wink, M. (2019). Chlorophyll and chlorophyll derivatives interfere with multi-drug resistant cancer cells and bacteria. Molecules, 24(16), art. no. 2968.

https://doi.org/10.3390/molecules24162968

46. Wiktor, A., Sledz, M., Nowacka, M., Rybak, K., Witrowa-Rajchert, D. (2016). The influence of immersion and contact ultrasound treatment on selected properties of the apple tissue. Applied Acoustics, 103 Part B, 136-142.

https://doi.org/10.1016/j.apacoust.2015.05.001

47. Witrowa-Rajchert, D., Wiktor, A., Sledz, M., Nowacka, M. (2014). Selected emerging technologies to enhance the drying process: A review. Drying Technology, 32(11), 1386-1396. https://doi.org/10.1080/07373937.2014.903412

48. Xiao, H.-W., Pan, Z., Deng, L.-Z., El-Mashad, H.M., Yang, X.-H., Mujumdar, A.S., Gao, Z.J., Zhang, Q. (2017). Recent developments and trends in thermal blanching - A comprehensive review. Information Processing in Agriculture, 4(2), 101-127. https://doi.org/10.1016/j.inpa.2017.02.001 